\title{
Using Online Practice Spaces to Investigate Challenges in Enacting Principles of Equitable Computer Science Teaching
}

\author{
Kevin Robinson \\ MIT Teaching Systems Lab \\ krob@mit.edu
}

\author{
Keyarash Jahanian \\ MIT Teaching Systems Lab
}

\author{
Justin Reich \\ MIT Teaching Systems Lab \\ jreich@mit.edu
}

\begin{abstract}
Equity is a core component of many computer science teacher preparation programs. One promising approach is addressing unconscious bias in teachers, which may impact teacher expectations and interactions with students. Since early intervention literature indicates that asking individuals to suppress biases is counterproductive, our work uses online interactive case studies as practice spaces to focus on teaching decisions that may be impacted by unconscious bias. Our initial findings indicate that when embedded within teacher preparation programs, practice spaces produce rich learning opportunities, and our analysis yields insights into how beliefs or biases may interfere with principles of equity like disrupting preparatory privilege.
\end{abstract}

ACM Reference format:

K. Robinson, K. Jahanian, and J. Reich. 2018. Using Online Practice Spaces to Investigate Challenges in Enacting Principles of Equitable Computer Science Teaching. In SIGCSE '18: 49th ACM Technical Symposium on Computer Science Education, Feb. 21-24, 2018, Baltimore, MD, USA. ACM, NY, NY, USA, 6 pages.

https://doi.org/10.1145/3159450.3159503

\section{INTRODUCTION}

Equity is a core component of many computer science teacher preparation programs, yet there remain considerable opportunity gaps for students in K12 computer science (CS) education in the United States [1]. Prior work emphasizes the long-term developmental nature of teacher cultural competency, and identifies key teacher beliefs around colorblindness, meritocracy, asset framing and intersectional conceptions of identity. These beliefs are entangled with the ways that teachers enact principles of equitable teaching in the classroom [1-4].

Another promising approach is targeting unconscious bias in teachers, particularly bias related to the race, ethnicity, or gender of students. This draws on interdisciplinary research from social psychology [5-6], behavioral economics [7], and educational

Permission to make digital or hard copies of all or part of this work for personal or classroom use is granted without fee provided that copies are not made or distributed for profit or commercial advantage and that copies bear this notice and the full citation on the first page. Copyrights for components of this work owned by others than the author(s) must be honored. Abstracting with credit is permitted. To copy otherwise, or republish, to post on servers or to redistribute to lists, requires prior specific permission and/or a fee. Request permissions fromPermissions@acm.org.

SIGCSE '18, February 21-24, 2018, Baltimore, MD, USA.

(C) 2018 Copyright is held by the owner/author(s). Publication rights licensed to ACM. ACM 978-1-4503-5103-4/18/02...\$15.00 .

https://doi.org/10.1145/3159450.3159503 research on bias within specific teaching decisions [8-11]. Early intervention literature indicates that asking individuals to suppress biases is counterproductive but recommends approaches that focus on empathy and individuation [12]. Simulation is one potentially powerful approach for encoding these strategies.

Prior work using clinical simulations to teach cultural competency requires several elements to be effective: authenticity, disequilibrium, self-reflection and discussion [3, 13]. This pedagogy creates additional opportunities for teachers to practice, since "knowledge plus practice is imperative" for developing cultural competency [2], and has been successfully adapted to online practice spaces with interactive case studies [14].

When enacting teaching decisions, teachers must interpret ambiguity within the situation and resolve conflicting principles and competing goals. Doing this within online practice spaces can reveal differences in teachers' pedagogical philosophies, skills and competencies, and frames they use to position students. Based on prior work [14] we hypothesize that practice spaces would create rich opportunities to investigate how teaching decisions may be influenced by unconscious bias.

Our work investigates two research questions: What kinds of teaching decisions do teachers make when given opportunities to enact principles of equitable teaching within online practice spaces? and What kinds of beliefs or biases interfere with teachers enacting principles of equitable teaching?

While there are many important principles of equitable teaching (e.g., inquiry-based pedagogy, culturally responsive curriculum), in this analysis we consider how teachers apply three specific principles to teaching decisions within practice spaces: positioning students with an asset framing, disrupting preparatory privilege, and honoring overlapping oppression in intersectional identities

Asset framing is when a teacher sees the knowledge and skills that culturally diverse students possess as strengths [5]. In contrast, deficit thinking positions students with differences as lacking, at-risk, or otherwise deficient. Asset orientation is "the lynchpin for instructional improvement" in teachers [15] and a key component of equity issues within CS [1].

Preparatory privilege, when a student has prior experience before entering the classroom, may be interpreted by teachers as a "natural gift" and influence the classroom climate negatively for other students [1]. Disrupting this privilege in classroom interactions is a key part of creating opportunity for all students, not just the "best and brightest" [1]. 
Intersectional identities are important aspects of students' lived experiences [16], and can influence how they experience the classroom, particularly in communities with unrepresentative populations like computer science. When students voice concerns or raise these issues, it's critical that teachers acknowledge and admit racial, ethnic, and gender identities into conversation [3].

\section{EXPERIMENTAL AND COMPUTATIONAL DETAILS}

\subsection{Learning Experience}

2.1.1 Context. Using design-based research methods [17], we deployed theoretically-informed prototypes of our simulations into increasingly high-fidelity and high-impact settings, from lab playtests, to small field tests, to program field tests.

This analysis focuses on aspects of five field tests conducted in workshops embedded within CS teacher preparation programs for in-service teachers. One field test was embedded within an undergraduate pre-service teacher education course. Overall, this includes data from 45 participants who consented to be included in research.

2.1.2 Participant Experience. Field tests were either in-person or blended, and were adapted in various smaller ways to fit the context. In all variations, workshop sessions used practice spaces to present teachers with challenging interactive scenarios that provoked disequilibrium, followed by reflection and discussion. In-person sessions required no preparation beforehand, and typically included a short introduction with the whole group, individual practice with the practice space, small group discussion, and then facilitated whole group discussion. Blended sessions consisted of individual practice done online before the session, followed by individual reflection, small group discussion, and facilitated whole group discussion during the session.

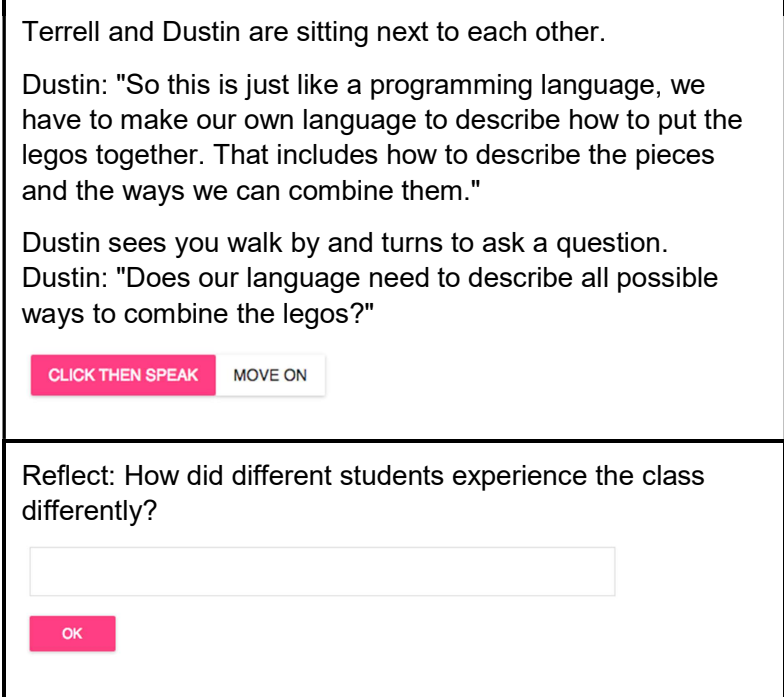

Figure 1: Examples scenes within the "Pairs" case study

\subsection{Data}

These sessions included different interactive case studies as the practice space; one was aimed at surfacing teacher bias in facilitating pair work ("Pairs") and another was aimed at practicing talking with students considering dropping a CS course ("Rosa"). The "Rosa" case study is a composite developed from conversations with high school computer science students, while "Pairs" was developed with input and feedback from teachers and teacher educators. Each case study presents multiple scenes and integrates multiple competencies. All case studies and scenes are accessible online and open source [18] with limited details shown in Figure 1, Table 1 and sections below.

2.1.3 Debriefs. Debriefs typically involved individual reflection, small group discussion and then facilitated whole group discussion. Examples of discussion questions included: How did you interpret what was happening in the scene? and What assumptions might teachers make about students that shape how they interact in the classroom? Closing reflections or survey questions included prompts like How would you explain to a firsttime teacher how bias can impact teachers? and How might unconscious bias related to students' race, ethnicity or gender impact how teachers respond in the classroom?

Table 1: Excerpts from "Rosa" case study
Rosa: "I mean, it's nice that there are more girls than guys in this class, but that doesn't change the fact that mostly nerdy white dudes and Asian dudes work in computer science."

Rosa: "Sure, there may be women in tech, but they're still mostly white women."

Rosa: "Well... I kinda feel like people are always surprised that I'm good at coding. It's like when Juanita and I did well on the first assignment, you made it feel like a big deal, but you didn't really say anything to anyone else. Brown girls can code, too, you know."

\subsection{Data Analysis}

2.2.1 Data sources. Our approach creates rich evidence for purposes of both formative assessment and research analysis, including: data recorded within the practice spaces during teacher reflections and responses, observations during small group and whole group discussions, posters and visuals that teachers created during sessions, and written responses to survey questions.

2.2.2 Analytic approach. We wrote software tools to combine response and reflection data in practice spaces with consent and survey forms. Researchers then used a grounded theory approach [19], reviewing responses and analyzing common themes that emerged from data, as well as coding particular responses for themes related to principles of equitable teaching. Direct quotes are used to illustrate these themes. 


\section{RESULTS AND DISCUSSION}

From the analysis of participant transcripts, log data, and survey responses, we briefly examine participant descriptions of their overall experience. We then describe how participant responses within practice spaces and subsequent discussion shed insight into challenges with enacting principles of equitable teaching. The principles we focus on are positioning students with an asset framing, disrupting preparatory privilege, and honoring overlapping oppression in intersectional identities. In those sections, we first discuss relevant details of case studies, various ways teachers successfully enacted the principle of equitable teaching in their responses to students, and then discuss influential beliefs or biases that may have impacted teachers who responded in less equitable ways. Quotations noted as being "in response" come from teachers' direct response to the simulation in text or recorded audio, those described as "in reflection" come from private text reflections, and those marked "in discussion" come from small group discussion, whole group discussion or related written artifacts like posters.

\subsection{Authenticity as Prerequisite for Learning}

In order to create meaningful learning experiences, practice spaces need to be situated coherently within the teacher preparation program, and to feel like authentic and relevant challenges to educators [13]. Teachers responded that they saw their role as a facilitator, coach or guide in $93 \%$ of responses across two field tests that included this in reflection questions $(n=14)$, indicating coherence between the practice space and the inquiry-based pedagogical philosophy of CS programs.

Teacher reports in surveys have been generally positive in terms of authenticity, usefulness for learning, and overall pedagogical approach. In three field tests with surveys, $88 \%$ of participants $(n=24)$ described the experience as helping them to learn something new or gain new insight. Participants nearly universally participated authentically within the scenario, responding in character to the students in the prompts, completing other elements of the simulation, and engaging meaningfully in discussions. One teacher wrote in the survey "Fascinating and very believable scenario! It was easy to put myself in the teacher's seat," and one teacher educator observed, "That feels like a pretty typical classroom... they loved the experience."

Participants also highlighted the benefits of practice over discussion alone, and the particular relevance of practice-based approaches for equity. One teacher wrote, "We've discussed issues of bias in my district PD [professional development], but it was helpful to talk about specific scenarios in computer science."

\subsection{Positioning students with an asset framing}

3.2.1 Case studies. The "Pairs" case study presents scenes where different sets of students are doing pair work together (e.g., Dustin/Terrell and Molly/DeShawn), as pair programming is a common instructional strategy where equity issues can arise [20]. Several scenes include one partner either demonstrating preparatory privilege or engaging more actively than the second, and potentially marginalizing the second student in the process.

3.2.2 Responses enacting equitable teaching. Teacher responses that enacted principles of equitable teaching included: speaking to students as a team, calling out collaboration as a critical skill for careers in CS, suggesting or requiring role changes, and encouraging students to pull back and make space for their partner to contribute.

3.2.3 Influential beliefs or biases. Teacher responses and reflections suggested that how teachers positioned students may be influenced by how teachers interpret differences in ability within pairs, and may be influenced by bias related to the student's gender or racial identities. Teacher beliefs around collaboration stressing individual accountability rather than joint responsibility may interfere with equitable facilitation as well

Student disengagement is driven by a student's interest or ability level in CS. In one field test $79 \%$ of participants responded in a way that positioned one student in the dyad as unmotivated or incompetent based solely on his lack of engagement with a peer who was demonstrating preparatory privilege and asking to work on his own $(\mathrm{n}=14)$. This is similar to findings around deficit thinking in [1] and may be influenced by racial bias. One teacher characterized inactivity as an essential quality of the student, reflecting that, "Terrell was just not interested... Terrell is clearly tuned out for some reason and it could be because of race, class, or ethnicity." This interfered with connecting Terrell's level of engagement to Dustin's expression of preparatory privilege and request to instead work on his own.

In group work, students primarily own responsibility for their own individual engagement. This belief may have interfered with teachers noticing how engagement is situated within group dynamics. Pre-service teachers in particular tended towards interpretations that positioned students who were less engaged as having deficits (e.g., "not knowing what was going on" or without "the ability to step up and to work") or blamed them for their position within the group dynamic (e.g., Molly "letting their partners take over the work" or being "okay with being in the background"). In one field test, $85 \%$ of students noticed that there was some kind of imbalance in the group dynamic between Molly and DeShawn, but $69 \%$ responded in a way that either positioned Molly as unmotivated or incompetent. How teachers placed responsibility for collaboration within the group interfered with seeing strengths in all students, and within each pair this may have been influenced by gender bias (Molly/DeShawn) or racial bias (Terrell/Dustin).

Teachers can respond in various ways that teach classroom norms around collaboration, a critical element of doing so equitably is positioning all students with an asset framing during collaboration. Beliefs around student interest and expectations around collaboration may influence how teachers position students, and these effects may be compounded by bias. 


\subsection{Disrupting preparatory privilege}

3.3.1 Case studies. In this section we analyze elements of two case studies. The "Pairs" case study presents moments of students collaborating on pair work, and three scenes are analyzed here for disrupting preparatory privilege. In each case, one student either takes over the group or expresses some form of preparatory privilege, and the other student is not actively collaborating or participating. The "Rosa" case study presents teachers with an opportunity to have a one-on-one conversation with a student considering dropping the CS course (see Table 1).

3.3.2 Responses enacting equitable teaching. Many responses to the "Pairs" case study were similar to those previously mentioned. Additional responses included: highlighting that the purpose of the lesson is to use languages as a tool for communicating with others, placing responsibility on the student with preparatory privilege to actively collaborate with their partner, and encouraging students to speak up and advocate for their own participation within the group. In the "Rosa" case study equitable responses included: respecting and honoring feelings of exclusion, allowing racial, ethnic and gender identity into the conversation, and projecting that productive struggle is normal and that you'll support the student and expect them to succeed.

3.3.3 Influential beliefs or biases. Within the "Pairs case study" teacher responses surfaced beliefs related to meritocracy and effective collaboration, which may have be influenced by racial bias (Dustin/Terrell) and gender bias (DeShawn/Molly). Within the "Rosa" scenario, analysis revealed beliefs around student choice and how students experience color blindness.

"High-flying" students have promising academic and career trajectories that should be encouraged. Philosophies of education that center on serving "the best and brightest" are common, but these are at odds with the conceptualization of equity in most CS teacher preparation problems [1]. In moments when students expressed preparatory privilege, some teachers responded in a way that contributed to further marginalizing students without that privilege. One teacher responded to Dustin and Terrell with only encouragement for Dustin (e.g., "Hey Dustin, what are you writing? ...let me know if you have any questions. Keep up the good work!"). Despite Dustin never speaking to his partner, the teacher reflected that "All belonged. None excluded," during the lesson. Another teacher directly questioned whether teachers should be disrupting preparatory privilege out of concerns for that student's ego and how it might impact their future career trajectory. Referring to DeShawn and Molly, they asked in discussion "Why not let him take over? [He could be a] future neuroscientist with an ego ready to go. You want ego operating on you." These beliefs interfered with disrupting preparatory privilege and may have been influenced by bias related to the student's gender (DeShawn/Molly) or race (Dustin/Terrell)

One effective approach to collaboration is to divide work based on group members' existing skills and strengths. When facilitating group interactions, some teachers characterized pairs as dividing work to suit each student's strengths. This may be appropriate in some adult circumstances where efficiency is a primary concern (and parallels prior work in how speed and time pressure influence equitable collaboration [20]), but is at odds with creating learning opportunities for all students. In CS classrooms with inquiry as the central pedagogy, dividing work based on current abilities misses the critical learning functions that communication and collaboration serve. Interpretations for how students should divide work and responsibility may also be influenced by gender bias. One teacher expressed in discussion that "maybe the way that DeShawn and Molly divided up the project was good, where they had [DeShawn] doing their strengths in building and [Molly] doing their strength in being organized." Another teacher described writing that Molly had done as "DeShawn's directions," suggesting potential bias related to gender roles within the group.

Teachers should respect student choice and not push other agendas on them. In the "Rosa" case study, this theme occurred in opposition to active recruitment and retention, which was framed as artificial and imposed on teachers (e.g. "first things [our CS teacher prep program] told us: jobs, women, need women... [but] if it isn't [a student's] cup of tea, it isn't..."). One teacher expressed concern that active recruiting was the result of people in CS "projecting onto students." There are many positive aspects to encouraging student autonomy and choice, and treating students as individuals with their "own unique attributes" is consistent with anti-bias recommendations [12]. Nevertheless some teachers used this belief to suggest there was little they could do if class enrollment consisted only of white male students. Another teacher suggested that this was because "there are some students who have zero interest in college... Some frankly don't care. Some guys are great at CS, [and] they're diesel mechanics [now]." Ethnic, racial, and gender bias may have influenced whether teachers accepted these lower expectations as "student choice" for particular students [13].

Recruiting or encouraging students because of their race, ethnicity or gender will make students feel uncomfortable. Teachers shared personal stories about how this was unsettling in their own lives, with one white female teacher saying in discussion that active recruiting "downplays [that] I'm smart and can add to society." She told how as a former engineering student she felt that teachers "just wanted me because I'm a woman, I'm a stat," and another teacher agreed that, "Rosa is now feeling singled out and pressured because of the bias of the teacher. Teacher made a bigger deal than if other students were performing well." Some teachers overgeneralized these important concerns about overpraising students into beliefs about treating all students the same way. This also led to comments in discussion that active recruiting should be based on current ability and colorblind (e.g., "forget being a minority, I take you as a person not "because you're Hispanic you can do it."").

In summary, teachers faced challenges with disrupting preparatory privilege both within classroom situations and with 
efforts towards actively recruiting and retaining a representative computer science class.

\subsection{Honoring overlapping oppression in intersectional identities}

3.4.1 Case studies. In this section we analyze additional elements of the "Rosa" case study.

3.4.2 Responses enacting equitable teaching. Themes in teacher responses to this aspect of the "Rosa" case study included: connecting to other role models, acknowledging that Rosa's concerns are legitimate, apologizing for creating a classroom environment that felt unwelcoming, encouraging Rosa that she can be involved in changing who is seen as using computers, while honoring that she may not choose that path.

3.4.3 Influential beliefs or biases. In the "Rosa" scenario teachers expressed beliefs around how simple changing representation issues in computer science will be, the central role of individual achievement in systemic change, and misconceptions of how students' intersectional identities influence career opportunities.

Representation issues within CS aren't significant. While downplaying these challenges may be a helpful approach for encouraging or creating confidence in students, this belief appeared to lead teachers towards making appeals towards colorblind meritocracy and dismissing student concerns. Some responses exaggerated how quickly systemic change can happen (e.g., "Well, that's been true in the past and it's not always going to be that way... that's not a reason to leave a class"). Another teacher challenged Rosa's concerns around representation, saying "I think that it doesn't take a particular person from a particular background or race to make it in tech, it's just a matter of working hard and being smart as you are... it's the people with the tech skills who are gonna go farther, so it almost sounds to me like you're limiting yourself..." These responses interfered with teachers acknowledging and validating Rosa's concerns around equity within the field.

Students should focus on their own individual achievement, and not need to seek belonging in academic of professional communities. Similar to optimistically encouraging students, several teachers emphasized that she focus only on what she had agency over as an individual, and ignore others in the community. To a certain extent, this is reasonable advice for people in low-power situations, but it also accepts perpetuating the power relationship. More importantly, this belief also functioned to dismiss Rosa's concerns and cut off discourse about representation issues or structural barriers in access to CS. One teacher asked Rosa "Are you here to socialize or are you here to learn computer science? ... If you're here to learn computer science who cares who's in this class?" Another said to Rosa that it was "very stereotypical" and "slightly sexist" when she named representation issues. Finally, one teacher dismissed Rosa's concerns about women in CS being mostly white by saying, "if you think about that then you're really limiting yourself." These beliefs about an individual's own agency to achieve may indicate unconscious biases about who belongs in CS or who deserves access to supportive academic and professional communities.

Young people with underrepresented racial, ethnic or gender identities have an advantage when pursuing career pathways involving computer science. Some teachers responded to Rosa's concerns about representation in computer science and intersectional oppression for Hispanic young women by highlighting active recruitment efforts by technology companies. One teacher responded to Rosa that "[tech companies are] screaming for minority ladies, and I'm pretty sure you check off all those boxes... they're looking for minority women... Facebook, the eBays, Amazon, or any other company that needs programmers they want you." The belief that limited recruitment efforts create an outsized advantage led to the teacher dismissing the student's concerns about representation, and real challenges with pursuing pathways in computer science.

Discussing course selection, college and career pathways, and other life choices with young people is a challenging aspect of teaching. In fields like CS that face equity issues, enacting principles of equitable teaching in conversation with students can be impacted by beliefs echoed in society outside of CS teacher education communities. These beliefs may also interact with teacher unconscious bias, particularly with assumptions about who computer science is "for."

\section{CONCLUSIONS}

We have performed an initial investigation into how online practice spaces can create rich learning opportunities for teachers to enact principles of equitable teaching. Our analyses of teacher responses and reflections provide important insights into teacher beliefs that can both support and hinder development of equity. Our findings suggest that teacher beliefs around colorblindness, meritocracy, and individual accountability may interfere with enacting principles of equitable teaching. We have also identified where beliefs and teaching decisions may be influenced by bias, and close by sharing four overarching themes related to teacher bias that cut across case studies and field tests.

First, framing bias as "assumptions" improved teacher participation and helped avoid challenges related to teacher beliefs around colorblindness. We iteratively refined field tests to being using "assumptions" and to de-emphasize or gradually introduce "bias" as a term. In discussions of assumptions, teachers readily identified various forms of assumptions unrelated to race, ethnicity or gender, and generally characterized making these kinds of assumptions as negative. This appeared to be supported by strong beliefs about the importance of building relationships and getting to know students as individuals.

Second, building towards talking directly about how racial, ethnic or gender bias can impact teaching is challenging. Even with unconscious bias, this ultimately involves socially undesirable behavior-a teacher has to name race, ethnicity or 
gender and express the possibility that they made negative assumptions related to that group. Instead of taking this path, using practice spaces served as a shared experience for small groups of teachers, creating a neutral space for reflection on the different ways that teachers responded. This demonstrated experientially that even in the same situation, teachers make different assumptions and interpretations, and that this drives the different teaching decisions that teachers make. All this serves to normalize assumptions as natural, inevitable, and consequential.

Third, teachers often avoid language around race, ethnicity and gender when understanding and describing scenarios, preferring to analyze and discuss situations on the safer grounds of motivation and aptitude. Given a variety of competing interpretations from teachers, this creates ideal learning opportunities for reflection and discussion about what direct evidence there is for various interpretations. Teachers can inquire individually or together as to how their own assumptions influence this process. If teachers are making assumptions related to bias, they can avoid naming those aloud by raising their awareness of this process and by practicing individuation. During discussion, facilitators can also raise the possibility that race, ethnicity or gender influence these interpretations without blaming any individual teachers.

Fourth, and perhaps most importantly, teachers face a complex set of tradeoffs and dilemmas in promoting equityteachers must respect student autonomy while encouraging participation, must treat students as individuals while recognizing racial dynamics. Development is more complex than simple skill acquisition or linear progression along trajectories. Teacher growth interacts with deeply held beliefs, and these beliefs may be expressed very differently in slightly different contexts. A deeper understanding of decisions impacting equity offers teacher educators and researchers new leverage into supporting teachers in their development towards equitable teaching.

Future work might extend this analysis and look at individual differences in teacher responses and reflections related to their racial, ethnic or gender identity. Trials with larger participant pools would strengthen the generality of these claims and allow more quantitative analysis methods. Additional field studies could investigate correlations with other measures of these beliefs like the Opportunity Gaps Survey, or even investigate if this survey is predictive of teacher responses within online practice spaces. Longer-term, an intriguing question is whether teacher performance within practice spaces is predictive of teaching decisions within classroom observation protocols or of perceptions' of bias and equity expressed in student surveys.

\section{ACKNOWLEDGMENTS}

We are grateful to Google for supporting case study development and field tests, to the Woodrow Wilson National Fellowship for supporting platform development, and to the CS education organizations, schools, and teachers who participated in this work.

\section{REFERENCES}

[1] Margolis, J. et al. 2010. Stuck in the Shallow End: Education, Race, and Computing. MIT Press.

[2] Gay, G. 2010. Culturally Responsive Teaching: Theory, Research, and Practice. Teachers College Press.

[3] Self, E.A. 2016. Designing and Using Clinical Simulations to Prepare Teachers for Culturally Responsive Teaching. Ph.D. Dissertation. Vanderbilt University, Nashville, TN.

[4] Richard Milner, H. 2010. Start where You Are, But Don't Stay There: Understanding Diversity, Opportunity Gaps, and Teaching in Today's Classrooms. Harvard Education Press.

[5] Forscher, P.S. et al. 2017. Breaking the prejudice habit: Mechanisms, timecourse, and longevity. Journal of experimental social psychology. 72, (Sep. 2017), 133-146.

[6] Lai, C.K. et al. 2016. Reducing implicit racial preferences: II. Intervention effectiveness across time. Fournal of experimental psychology. General. 145, 8 (Aug. 2016), 1001-1016.

[7] Bertrand, M. and Duflo, E. 2017. Field experiments on discrimination. Handbook of Economic Field Experiments. 1, (2017), 309-393.

[8] Gershenson, S. et al. 2016/6. Who believes in me? The effect of student-teacher demographic match on teacher expectations. Economics of education review. 52, (2016/6), 209-224.

[9] Axt, J. et al. 2016. The Judgment Bias Task: A reliable, flexible method for assessing individual differences in social judgment biases. (2016).

[10] Glock, S. 2016. Stop talking out of turn: The influence of students' gender and ethnicity on preservice teachers' intervention strategies for student misbehavior. Teaching and Teacher Education. 56, (May 2016), 106-114.

[11] Okonofua, J.A. and Eberhardt, J.L. 2015. Two strikes: race and the disciplining of young students. Psychological science. 26, 5 (May 2015), 617-624.

[12] Dee, T., and Gershenson, S. 2017. Unconscious Bias in the Classroom: Evidence and Opportunities. Mountain View, CA: Google Inc. Retrieved from https://goo.gl/O6Btqi.

[13] Dotger, B.H. 2013. I Had No Idea: Clinical Simulations for Teacher Development. IAP.

[14] Owho-Ovuakporie, K. and Others 2017. Using "Teacher Moments" as an Online Practice Space for Parent-teacher Conference Simulation in Preservice Teacher Education. (2017).

[15] Horn, I. 2017. An Asset-Orientation is Everything: How StrengthsBased Perspectives on Math Teaching Help Students -- and Teachers (February 2017). Retrieved September 1, 2017 from https://csme.utah.edu/wp-content/uploads/2017/02/Horn-HugoRossi-Lecture-2017.pdf

[16] Crenshaw, K. 1991. Mapping the Margins: Intersectionality, Identity Politics, and Violence against Women of Color. Stanford law review. 43, 6 (1991), 1241-1299.

[17] Easterday, M. et al. 2014. Design-based research process: Problems, phases, and applications. Proc. of International Conference of Learning Sciences (2014).

[18] GitHub. 2017. Retrieved from https://github.com/mit-teachingsystems-lab/threeflows.

[19] Charmaz, K. 2014. Constructing Grounded Theory. SAGE.

[20] Lewis, C.M. and Shah, N. 2015. How Equity and Inequity Can Emerge in Pair Programming. Proceedings of the Eleventh Annual International Conference on International Computing Education Research (New York, NY, USA, 2015), 41-50. 